\title{
Lettuce mosaic virus Pathogenicity Determinants in Susceptible and Tolerant Lettuce Cultivars Map to Different Regions of the Viral Genome
}

\author{
Elise Redondo, ${ }^{1}$ Renate Krause-Sakate, ${ }^{1}$ Shu-Jun Yang, ${ }^{1}$ Hervé Lot, ${ }^{2}$ Olivier Le Gall, ${ }^{1}$ \\ and Thierry Candresse ${ }^{1}$ \\ 'Virologie, UMR GDPP, IBVM, INRA, BP 81, 33883 Villenave d'Ornon Cedex, France; 2 Pathologie Végétale, \\ INRA, Domaine St. Maurice, BP 94, 84143 Montfavet Cedex, France \\ Submitted 29 November 2000; Accepted 8 February 2001.
}

Full-length infectious cDNA clones were constructed for two isolates (LMV-0 and LMV-E) of Lettuce mosaic virus (LMV), a member of the genus Potyvirus. These two isolates differ in pathogenicity in susceptible and tolerantresistant lettuce cultivars. In susceptible plants, LMV-0 induces mild mosaic symptoms, whereas LMV-E induces severe stunting, leaf deformation, and a necrotic mosaic. In plants carrying either of the two probably allelic recessive resistance genes $\mathrm{mol}^{1}$ or $\mathrm{mol}^{2}, \mathrm{LMV-0}$ is restricted partially to the inoculated leaves. When a systemic invasion does occur, however, symptoms fail to develop. LMV$E$ overcomes the protection afforded by the resistance genes, resulting in systemic mosaic symptoms. Analysis of the behavior of recombinants constructed between the two virus isolates determined that the HC-Pro protein of LMV-E causes the severe stunting and necrotic mosaic induced by this isolate in susceptible cultivars. In contrast, the ability to overcome mol resistance and induce symptoms in the resistant-tolerant cultivars was mapped to the $3^{\prime}$ half of the LMV-E genome. These results indicate that the ability to induce severe symptoms and to overcome the protection afforded by the recessive genes $\mathrm{mol}^{1}$ or $\mathrm{mol}^{2}$ are independent phenomena.

Additional keywords: 35S, leaf necrosis, resistance breaking, VPg.

Lettuce mosaic virus (LMV) is one of the most destructive viruses in lettuce and endive field crops worldwide (Dinant and Lot 1992). LMV belongs to the genus Potyvirus, and its genome consists of a positive-strand RNA of 10,080 nucleotides (Revers et al. 1997a). The RNA genome of potyviruses is $3^{\prime}$ polyadenylated, linked to a viral protein $(\mathrm{VPg})$ at its $5^{\prime}$ end, and codes for a single large polyprotein that is processed

Corresponding author: O. Le Gall; Telephone: +33 5568432 05; Fax: +33 5568432 21; E-mail: legall@ bordeaux.inra.fr

Present address of S.-H. Yang: Plant Biology Division, Samuel Roberts Noble Foundation, P.O. Box 2180, Ardmore, OK 73402, U.S.A.

* The $\boldsymbol{e}$-Xtra logo stands for "electronic extra," indicating that the article online contains links to Web sites not included in the print edition. further by three virus-encoded proteinases (Dougherty et al. 1990; Reichmann et al. 1992). Phenotypic variability has been described in LMV, especially in terms of virulence (Bos et al. 1994; Pink et al. 1992a; Revers et al. 1997b). Specifically, LMV isolates have been classified into four pathotypes, according to their virulence on lettuce varieties carrying the three resistance or tolerance genes $\mathrm{mol}^{1}, \mathrm{~mol}^{2}$, and $\mathrm{Mo}$, which are identified in Lactuca sativa cultivars (Bos et al. 1994; Pink et al. 1992a). The $\mathrm{mol}^{1}$ and $\mathrm{mol}^{2}$ genes are recessive and believed to be either closely linked or allelic (Dinant and Lot 1992). These resistance genes are deployed worldwide and allow for reasonably effective control of the disease, although resistance-breaking isolates such as LMV-E have been reported (Pink et al. 1992b) and constitute a threat to the lettuce-growing industry. Depending upon the particular virus isolate and/or host cultivar combination, the presence of mol recessive genes results in resistance (no detectable virus multiplication) or tolerance (virus accumulation but failure to induce significant symptoms) (Pink et al. 1992b; Revers et al. 1997b).

In susceptible cultivars, LMV isolates also differ in their pathogenicity, namely in the severity of the symptoms they induce. For instance, most LMV isolates induce distinct but relatively mild mosaic symptoms in the susceptible cultivar Trocadéro, whereas others such as LMV-E (Pink et al. 1992a) induce severe mosaic symptoms accompanied by localized leaf necrosis, leaf deformation, and general stunting of the infected plants. LMV-E is, therefore, able to induce symptoms on cultivars carrying $\mathrm{mol}^{1}$ or $\mathrm{mol}^{2}$ as well as severe symptoms in susceptible lettuce cultivars. The determination of the complete nucleotide sequence of two isolates, LMV-E and LMV-0 (a non-resistance-breaking, standard symptomatology isolate), showed $97 \%$ homology at the protein level (Revers et al. 1997a). In this study, we used recombinant isolates constructed between LMV-0 and LMV-E in a reverse genetics approach to address the question of whether these properties are the result of a single plant-virus interaction mechanism with different intensities in different cultivars or of two distinct mechanisms.

The construction of a full-length infectious cDNA clone for LMV-E genomic RNA has previously been reported (Yang et al. 1998). The infectious LMV-0 cDNA was obtained simi- 
larly by the stepwise assembly of partial cDNA clones selected from the cDNA library used previously to determine the LMV-0 sequence (Revers et al. 1997a) and of two reverse transcription-polymerase chain reaction fragments, covering nucleotides 1 to 692 and 4,650 to 5,494, respectively.

Full-length cDNA clones were first inoculated onto fourleaved-plantlets of the susceptible cultivar Trocadéro. For this purpose, approximately $100 \mathrm{ng}$ of plasmid was precipitated for 10 min with $100 \mu \mathrm{l}$ of $1 \mathrm{M} \mathrm{CaCl}_{2}$ onto gold particles of $1 \mu \mathrm{M}$ diameter (Bio-Rad, Hercules, CA, U.S.A.) in the presence of $100 \mu \mathrm{l}$ of $0.05 \mathrm{M}$ spermidine. After three washes with $1 \mathrm{ml}$ of fresh $100 \%$ ethanol each time, the pellet was resuspended in $600 \mu \mathrm{l}$ of $0.05 \%$ polyvinylpyrrolidone in ethanol. The mixture was placed in a plastic tube (Bio-Rad) and dried with a continuous flow of nitrogen. The gold particles coated with cDNA were then projected onto young lettuce leaves with the BioRad Helios Gene gun, set at a helium pressure of $180 \mathrm{psi}$. The plants showed typical vein-clearing symptoms 10 to 15 days postinoculation (dpi) and systemic mosaic symptoms within 3 weeks.

Samples of these plants were then ground in the presence of 3 volumes of $\mathrm{Na}_{2} \mathrm{HPO}_{4} 25 \mathrm{mM}$, DIECA $2 \%$ and, after the addition of charcoal (400 mg per gram of leaf) and carborundum (400 mg per gram of leaf), were used to mechanically inoculate assay lettuce plantlets belonging either to Trocadéro or to one of the resistant-tolerant cultivars Floribibb $\left(\mathrm{mol}^{1}\right)$ or Salinas $88\left(\mathrm{~mol}^{2}\right)$.

LMV-0 typically causes vein clearing on the first new leaves after inoculation and mosaic on the following leaves in the susceptible cultivar Trocadéro (Dinant and Lot 1992). The vein clearing caused by LMV-E is somewhat more intense. Later, the mosaic caused by LMV-E on this cultivar also is accompanied by vein necrosis, leaf distortion, and a general stunting of the plant (Fig. 1A). The plants inoculated biolistically with the cloned, full-length cDNAs of LMV-0 and LMV$\mathrm{E}$ or rub inoculated with the progeny virus found in these primarily infected plants became infected and developed symptoms indistinguishable from those rub inoculated with the parental viruses.

In the cultivars carrying the $m o l^{1}$ or $m o l^{2}$ genes, LMV-0 does not induce symptoms, whereas LMV-E infection results in the appearance of a systemic mosaic at 15 to 20 dpi (Fig. $1 \mathrm{~B}$ and data not shown). Contrary to what is observed in Trocadéro plants, LMV-E symptoms in the resistant lettuce cultivars assayed are not as severe and usually non-necrotic. The mol ${ }^{1}$-carrying cultivar Floribibb, however, shows a clear necrotic reaction 30 dpi with LMV-E (not shown).

The accumulation levels of LMV-0 and LMV-E in the infected plants were estimated by dot-blot hybridization in two independent experiments (Fig. 2) (Brault et al. 1993). Variability in the virus accumulation levels was observed within and between the experiments. In the susceptible cultivar Trocadéro, however, all plants inoculated became infected, irrespective of the viral isolate used, and LMV-0 accumulated to levels similar or higher to those reached by LMV-E (Fig. 2A). On the contrary, in cultivars carrying the $\mathrm{mol}^{1}$ or $\mathrm{mol}^{2}$ genes, LMV-0 showed an erratic behavior: systemic accumulation was detected in two or three out of four and inoculated plants of the $\mathrm{mol}^{2}$-carrying cultivar Salinas 88 (Fig. 2B), whereas no systemic accumulation was detected in the $\mathrm{mol}^{1}$-carrying cultivar Floribibb (Fig. 2C). This erratic behavior was always observed and is consistent observed and is consistent with previous observations showing that $\mathrm{mol}$ genes can afford either resistance or tolerance to LMV infection (Bos et al. 1994; Dinant and Lot 1992; Revers et al. 1997b). Despite the variations in accumulation, it also can be concluded that in Salinas 88, where systemic LMV-0 accumulation was detected in some plants, the levels reached were generally lower than those achieved by LMV-E (Fig. 2B).

The limited level of divergence between LMV-0 and LMV$\mathrm{E}$ at the nucleotide level (Revers et al. 1997a) results in the conservation of several unique restriction sites in their cDNAs. These restriction sites were used to exchange segments between the infectious cDNAs in order to construct recombinant infectious cDNA clones. The recombinant cDNAs obtained are shown in Figure 3, indicating the restriction sites used and their positions along the LMV genome. All the recombinants were infectious and systemically accumulate in the susceptible cultivar Trocadéro (Fig. 2A).

Although the majority of the recombinants accumulated to levels comparable to those reached by the parental LMV-0 and LMV-E viruses, a few of them showed consistently higher (Esph0) or lower (Ebsxh0) accumulation (Fig. 2A). A similar variability in accumulation levels has previously been observed between Pea seedborne mosaic virus (PSbMV) recombinants (Johansen et al. 1996).

Recombinants 0xbaE, Exba0 and 0sphE, and Esph0 resulted in the exchange of the $5^{\prime}$ and $3^{\prime}$ halves of the genome between LMV-0 and LMV-E (Fig. 3). On the susceptible cultivar Trocadéro, viruses Exba0 and 0 sphE induced a mosaic similar to that caused by LMV-0, whereas recombinants $0 \mathrm{xbaE}$ and Esph0 caused leaf distortion, stunting, and a necrotic mosaic similar to that induced by LMV-E (not shown). Thus, the symptoms caused by these recombinant viruses were similar to those induced by the isolate from which their $5^{\prime}$ region was derived.

To refine this analysis, a second set of recombinant pairs was constructed. The recombinant pair OrsbsE-Ersbs0 exchanged a region containing the $\mathrm{C}$-terminal three-fourths of the $\mathrm{P} 1$ protein together with the $\mathrm{N}$-terminal two-thirds of $\mathrm{HC}$ Pro, whereas recombinants 0bsxhE-Ebsxh0 exchanged the Cterminal third of HC-Pro together with the P3, 6K1, and almost all of the CI proteins (Fig. 3). The symptomatology of these recombinants in cultivar Trocadéro indicated that the determinant for symptom severity of LMV-E segregated with the P1-HC-Pro fragment (nucleotide positions 386 to 2,375 on the genome).

Finally, taking advantage of the presence of an AatII restriction site four nucleotides inside the region coding for HC-Pro, recombinants were constructed to evaluate whether the severe symptoms phenotype mapped to the P1 or the HC-Pro coding regions. Analysis of the symptoms caused by recombinants OrsaaE, Ersaa0, 0aabsE, and Eaabs0 unambiguously showed that the determinant of the severe necrotic symptoms induced by LMV-E maps to the amino-terminal two-thirds of the HCPro coding region, from nucleotide positions 1,422 to 2,375 (Figs. 1C to E, and 3). Surprisingly, recombinants OrsbsE and OaabsE showed a tendency to induce even more necrotic symptoms than the parental LMV-E isolate (Fig. 1C and E).

When analyzing the accumulation levels of all recombinants by dot-blot hybridization, no clear correlation between symptom severity and RNA concentration in systemic leaves 
was observed (Fig. 2A). Several symmetric pairs accumulated similarly, despite their difference in symptoms (pairs 0rsbsEErsbs0 or OrsaaE-Ersaa0), and the lowest accumulating recombinant, Ebsxh0, caused severe symptoms.

The results presented here show that the LMV-E genomic region carrying the symptom severity determinant in lettuce susceptible cultivar Trocadéro is located in the HC-Pro coding region between nucleotide positions 1,422 to 2,375 . In order to confirm these results, we inserted the $X b a \mathrm{I}, R s r \mathrm{II}-B s t \mathrm{EII}$, BstEII-XhoI, and AatII-BstEII fragments from another nonnecrotic, resistance-breaking isolate LMV-AF199 (Stangarlin et al. 2000) into LMV-E, again resulting in an ability to induce the necrotic mosaic symptoms characteristic of LMV-E segregating with the AatII-BstEII fragment (data not shown).
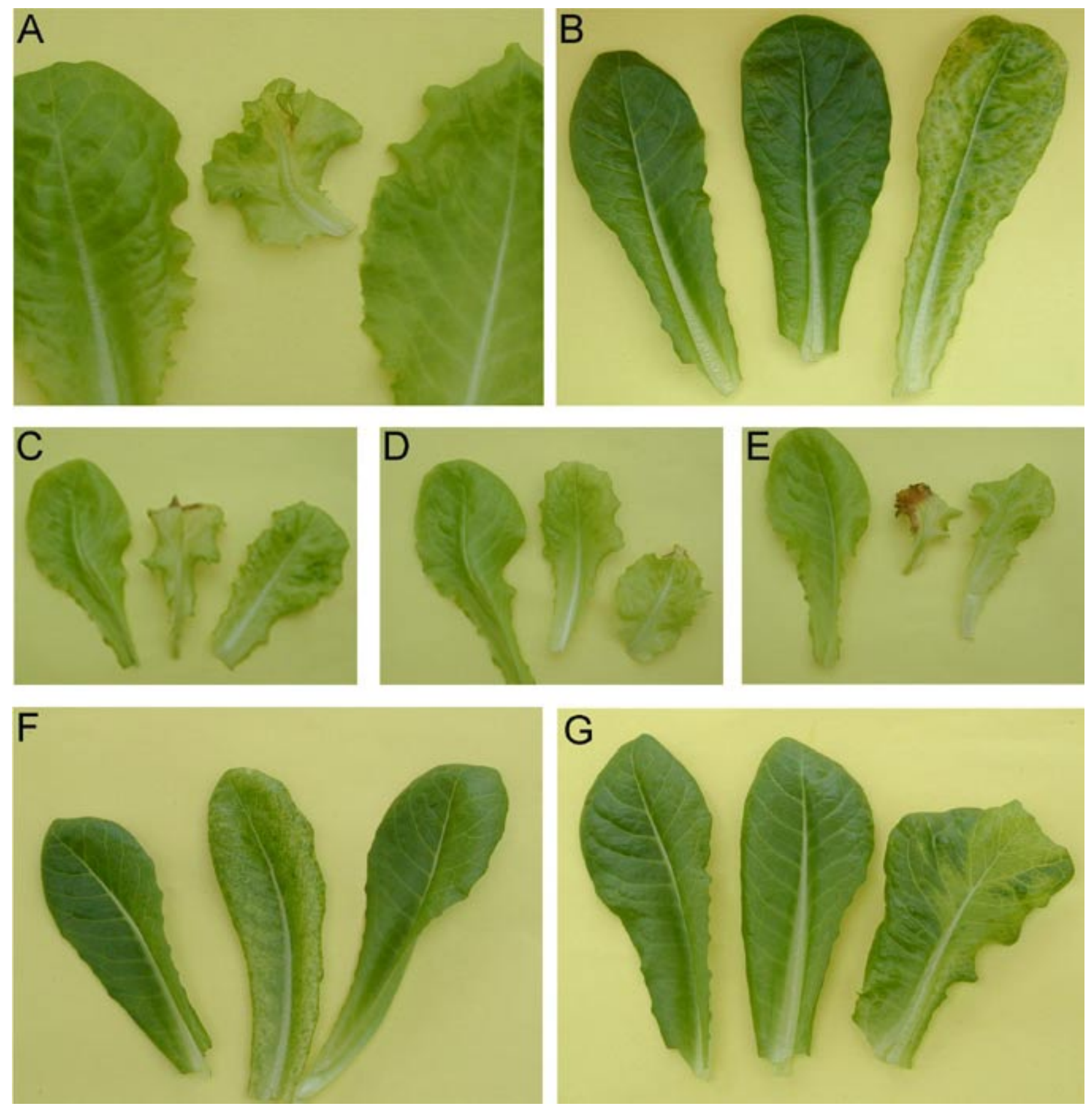

Fig. 1. Symptoms induced in apical leaves of lettuce by the parental isolates LMV-0 and LMV-E and by recombinant viruses derived from them. A, Susceptible cultivar Trocadéro 25 days postinoculation (dpi). Healthy control (left) infected with LMV-E (middle) or with LMV-0 (right). B, Resistant-tolerant cultivar Floribibb 20 dpi. Healthy control (left) infected with LMV-0 (middle) or with LMV-E (right). C-E, Comparison of symptoms induced on cultivar Trocadéro $20 \mathrm{dpi}$. A healthy control leaf is placed on the left in each figure. C, Infection with recombinants 0rsbsE (middle) or Ersbs0 (right). D, Infection with recombinants 0rsaaE (middle) or Ersaa0 (right). E, Infection with recombinants 0aabsE (middle) or Eaabs0 (right). F, Floribibb leaves at $20 \mathrm{dpi}$; healthy control (left) infected with recombinants 0xbaE (middle) or Exba0 (right). G, Floribibb at 20 dpi; healthy control (left) infected by recombinants 0 sphE (middle) or Esph0 (right). 
Involvement of HC-Pro in the determination of LMV symptoms severity in Trocadéro also was previously demonstrated indirectly by analysis of the biological properties of GUS or green fluorescent protein-tagged LMV-E derivatives, in which the reporter gene was fused to the $\mathrm{N}$ terminus of HC-Pro, and their spontaneous deletion variants (German-Retana et al. 2000). In the same manner, Dolja et al. (1992) have shown that fusion of the GUS gene at the $\mathrm{N}$ terminus of the HC-Pro sequence of Tobacco etch virus resulted in a drastic reduction in symptom severity on tobacco plants. In another report, mutations located in the $5^{\prime}$ or $3^{\prime}$ domain of HC-Pro of Tobacco vein mottling virus (TVMV) abolished the ability to induce severe symptoms (Klein et al. 1994). Although other symptom determinants of potyviruses were described along the genome (Revers et al. 1999b), HC-Pro seems to be a common determinant of symptom expression.

In several potyviruses, HC-Pro also has been identified as a suppressor of the RNA-mediated defense (RMD) (Baulcombe

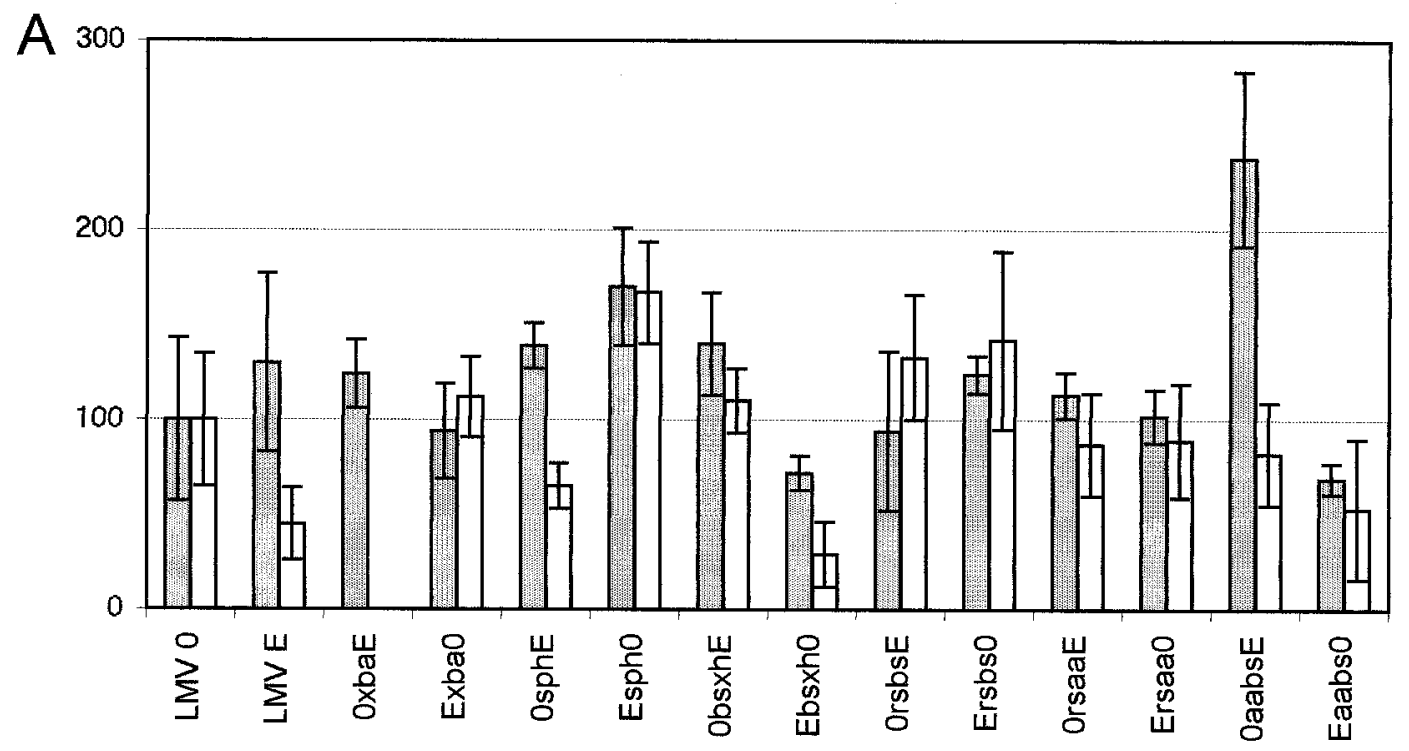

B

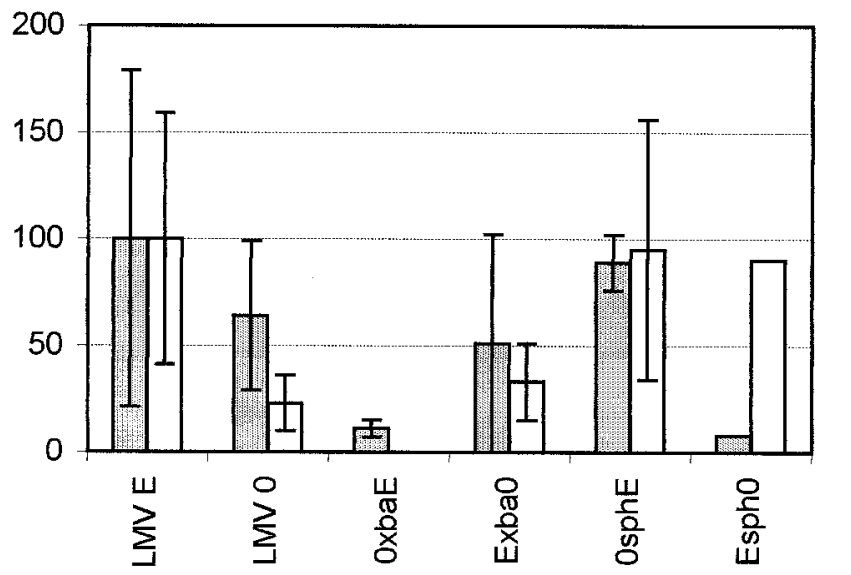

C

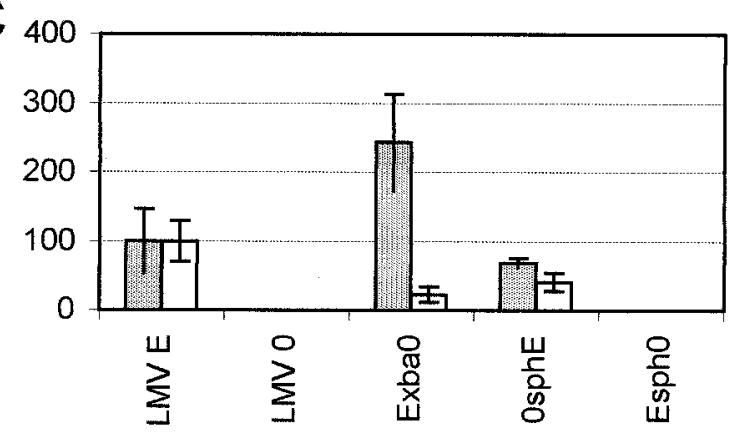

Infected plants/inoculated plants

\begin{tabular}{lcc}
\hline & 1st exp. & 2nd exp. \\
\cline { 2 - 3 } LMV E & $3 / 3$ & $3 / 3$ \\
LMV 0 & $2 / 4$ & $3 / 4$ \\
OxbaE & $2 / 3$ & nd \\
Exba0 & $2 / 2$ & $3 / 3$ \\
OsphE & $3 / 3$ & $4 / 4$ \\
Espho & $1 / 3$ & $1 / 3$
\end{tabular}

Fig. 2. Accumulation at 20 days postinoculation of parental isolates LMV-0 and LMV-E and the recombinant viruses on the susceptible lettuce cultivar Trocadéro (A) and resistant-tolerant cultivars Salinas 88 (B) and Floribibb (C). Accumulation of each virus was measured by dot-blot hybridization on three or four plants and in two independent experiments (grey and white bars, respectively). Results are expressed as a percentage of the average value measured for LMV-0 (A) or LMV-E (B and C). B, The number of infected plants for each experiment is indicated. 
1999). Indeed, several authors have provided evidence that the virulence factor activity of this protein is a result, at least in part, to the suppression of a host defense mechanism that is associated consistently with a higher accumulation level of the virus (Pruss et al. 1997; Shi et al. 1997; Vance et al. 1995). Here, however, no correlation between symptoms severity and viral accumulation was found (Fig. 2A). This argues against the hypothesis that the effects of LMV-E HC-Pro on symptoms is caused by an increased ability to suppress RMD.

Although the symptoms induced by LMV-0 and LMV-E are very different (Fig. 1A), the HC-Pro sequences of these two isolates are related closely, differing only in seven positions in the region identified as carrying the symptom determinant(s). Interestingly, these differences are scattered along the HC-Pro sequence but do not concern conserved motifs such as the FRNK block of amino acids implicated recently in symptom expression in Zucchini yellow mosaic virus (Gal-On 2000). Site-directed mutagenesis experiments are now under way to try to identify which of these amino acid changes is directly responsible for the severe infection phenotype of LMV-E.

Inoculation of the same set of recombinants onto cultivars carrying the $\mathrm{mol}^{1}$ (Floribibb) or $\mathrm{mol}^{2}$ (Salinas 88) resistancetolerance genes demonstrated that the ability to overcome the resistance afforded by these genes was carried in the $3^{\prime}$ region of the LMV genome between nucleotide positions 5,855 and 9,388. The recombinant viruses Exba0 and 0sphE caused symptoms typical of LMV-E infection on the cultivars carrying the mol genes, whereas the symmetrical recombinants 0xbaE and Esph0 failed to cause any symptoms on those same plants (Fig. $1 \mathrm{~F}$ and $\mathrm{G}$ for cultivar Floribibb and data not shown for Salinas 88 or other cultivars tested).

Evaluation of the accumulation levels of the progeny of each recombinant virus showed that in $\mathrm{mol}^{1}$-carrying cultivars, no systemic accumulation could be detected for recombinant Esph0 (Fig. 2C), reflecting the situation described above for LMV-0. The resistance-breaking recombinants ac-

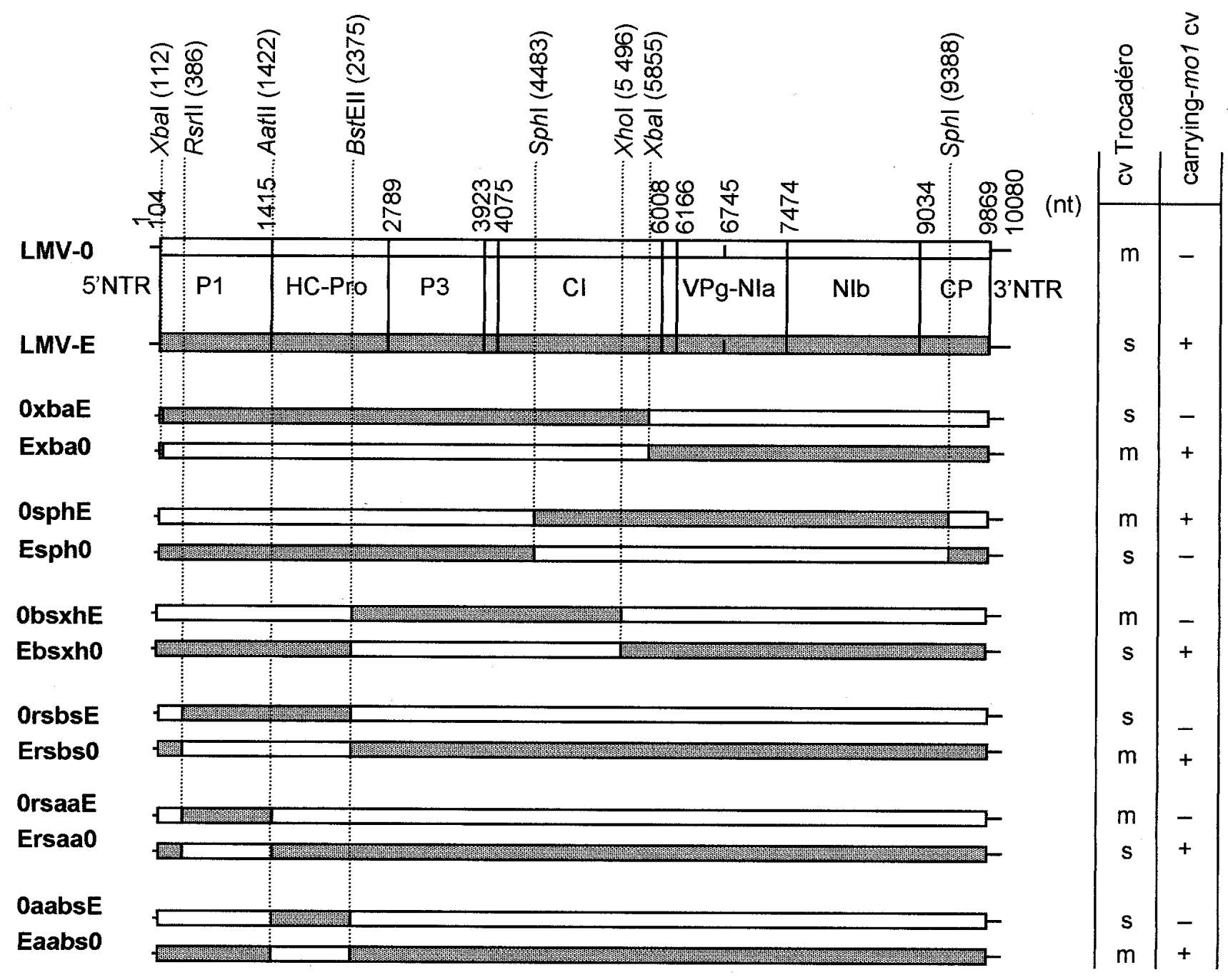

Fig. 3. Schematic representation of the genome of Lettuce mosaic virus and of the structure and pathogenicity of the recombinants constructed between LMV-0 and LMV-E. Coding sequences corresponding to LMV-0 and LMV-E are indicated with white and grey boxes, respectively. Restriction sites used to construct the recombinants and their position along the LMV genome are indicated at the top. The nucleotide position delimiting each coding region of the genome also are given. Summaries of the behavior of parental isolates of LMV and their chimeric recombinants on susceptible cultivar Trocadéro and on mol-carrying cultivar are indicated. $\mathrm{m}=$ mild symptoms; $\mathrm{s}=$ severe symptoms; $-=$ lack of symptoms; $+=$ presence of symptoms. 
cumulated to levels somewhat lower than those achieved by LMV-E, with the notable exception of one experiment where very high accumulation of recombinant Exba0 was observed.

In the $m o l^{2}$-carrying cultivar Salinas 88 , the non-resistance breaking-recombinants $0 x \mathrm{xaE}$ and Esph0 behaved erratically, similar to that observed previously for LMV-0, showing detectable but usually low accumulation in some of the inoculated plants and no accumulation in others (Fig. 2B). The resistance breaking recombinants accumulated to levels similar (0sphE) or lower (Exba0) than those reached by LMV-E in the same host.

In the same manner, all recombinants carrying the $3^{\prime}$ half of the LMV-E genome (Ebsxh0, Ersbs0, Ersaa0, and Eaabs0) were able to infect and induce symptoms in the cultivars Floribibb $\left(\mathrm{mol}^{1}\right)$ or Salinas $88\left(\mathrm{~mol}^{2}\right)$, whereas symmetric recombinants never caused symptoms in these cultivars at 20 dpi (data not shown and Fig. 3).

The 3 ' half of the LMV-E genome is the region that enables $100 \%$ systemic infection and induces symptoms on cultivars carrying the genes $\mathrm{mol}^{1}$ or $\mathrm{mol}^{2}$. It has not yet been possible to narrow down this region nor to separate the ability to overcome $m o l^{1}$ versus $m o l^{2}$. The resistance-breaking region identified here contains the very end of the CI protein as well as the $6 \mathrm{~K} 2, \mathrm{VPg}$, NIa-Pro, NIb, and the N-terminal half of the $\mathrm{CP}$. Contribution of the $\mathrm{CP}$ itself has been ruled out from sequence comparisons among a broad range of LMV isolates (Revers et al. 1997b; Revers et al. 1999a), but our data do not yet indicate which of the other protein(s) is actually involved.

The role of the VPg in overcoming several recessive resistance genes conferring different resistance phenotypes has been described (Revers et al. 1999b). This includes aspects as different as the ability of TVMV to move systemically in pepper plants containing the recessive $v a$ gene (Nicolas et al. 1997), the PSbMV multiplication in pea cultivars carrying the recessive $s b m-1$ gene (Keller et al. 1998), and the ability of Potato virus A to infect Nicandra physaloides (Rajamaki et al. 1999). The phenotype of mol resistance is another situation in which in certain specific viral isolate cultivar combinations, neither virus multiplication (PSbMV against $s b m-1$ ) nor virus cell-to-cell spread or systemic virus movement (TVMV against $v a$ ) are abolished (Bos et al. 1994; Dinant and Lot 1992; Revers et al. 1997b). Determining whether the LMV $\mathrm{VPg}$ is involved in overcoming this peculiar type of resistance-tolerance calls for further studies involving new recombinants or point mutants targeting this specific region.

Altogether, the results presented here show that the ability to induce symptoms on a tolerant-resistant cultivar carrying the $m o l^{1}$ or $m o l^{2}$ genes and the ability to induce severe symptoms on a susceptible cultivar are not controlled by the same region of the LMV-E genome. This observation strongly suggests that two different mechanisms are involved in these two biological properties, which are probably not functionally equivalent. This question arises from the primary observation that, in the pair of isolates selected for this study as well as for others (Revers et al. 1997b), a general correlation between symptom severity and resistance breaking was observed. In addition, given that the protection afforded by the mol genes is often of the tolerance type, resistance breaking could be conceived as resulting from an increase in symptom severity, from no visible symptoms to clear infection symptoms. This hypothesis, however, is clearly wrong, considering the bio- logical properties of recombinant pairs such as $0 \mathrm{xbaE}$ and Exba0, in which these two properties have been dissociated. Furthermore, 0xbaE produces severe and necrotic symptoms on the susceptible cultivar Trocadéro, yet is unable to provoke symptoms on the tolerant cultivars Floribibb $\left(m o l^{1}\right)$ and Salinas $88\left(\mathrm{~mol}^{2}\right)$, whereas the opposite is true for Exba0.

\section{ACKNOWLEDGMENTS}

We thank X. Capdevielle and T. Mauduit for their excellent technical assistance in the greenhouse, K. Richards and S. Blanc for useful discussions, and K. Mayo-Candresse for her help with the English in the manuscript. E. Redondo is a doctorate fellow of INRA and the Conseil Régional d'Aquitaine. R. Krause-Sakate is a doctorate fellow of CAPES (Brazil). S.-J. Yang was a doctoral fellow of the Chinese government and of INRA. This work was partially supported by the "PRFMMIP" program of the French Ministry of Research and by the Conseil Régional d'Aquitaine.

\section{LITERATURE CITED}

Baulcombe, D. 1999. Viruses and gene silencing in plants. Arch. Virol. Suppl. 15:189-201.

Bos, L., Huijberts, N., and Cuperus, C. 1994. Further observations on variation of lettuce mosaic virus in relation to lettuce (Lactuca sativa), and a discussion of resistance terminology. Eur. J. Plant Pathol. 100:293-314.

Brault, V., Candresse, T., Le Gall, O., Delbos, R. P., Lanneau, M., and Dunez, J. 1993. Genetically engineered resistance against grapevine chrome mosaic nepovirus. Plant Mol. Biol. 21:89-97.

Dinant, S., and Lot, H. 1992. Lettuce mosaic virus: A review. Plant Pathol. 41:528-542.

Dolja, V. V., McBride, H. J., and Carrington, J. C. 1992. Tagging of plant potyvirus replication and movement by insertion of $\beta$-glucuronidase into the viral polyprotein. Proc. Natl. Acad. Sci. USA 89:1020810212.

Dougherty, W. G., Parks, T. D., Smith, H. A., and Lindbo, A. 1990. Expression of potyvirus genome: The role of proteolytic processing. Pages 124-139 in: Viral Genes and Plant Pathogenesis. T. P. Pirone and J. G. Shaw, eds. Springer-Verlag, Vienna.

Gal-On, A. 2000. A point mutation in the FRNK motif of the potyvirus helper component-protease gene alters symptom expression in Cucurbits and elicits protection against the severe homologous virus. Phytopathology 90:467-473.

German-Retana, S., Candresse, T., Alias, E., Delbos, R.-P., and Le Gall, O. 2000. Effects of green fluorescent protein or $\beta$-glucuronidase tagging on the accumulation and pathogenicity of a resistance-breaking Lettuce mosaic virus isolate in susceptible and resistant lettuce cultivars. Mol. Plant-Microbe Interact. 13:316-324.

Johansen, I. E., Dougherty, W. G., Keller, K. E., Wang, D., and Hampton, R. O. 1996. Multiple viral determinants affect seed transmission of Pea seed-borne mosaic virus in Pisum sativum. J. Gen. Virol. 77:3149-3154.

Keller, K. E., Johansen, I. E., Martin, R. R., and Hampton, R. O. 1998. Potyvirus genome-linked protein (VPg) determines Pea seed-borne mosaic virus pathotype-specific virulence in Pisum sativum. Mol. Plant-Microbe Interact. 11:124-130.

Klein, P. G., Klein, R. R., Rodriguez-Cerezo, E., Hunt, A. G., and Shaw, J. G. 1994. Mutational analysis of the tobacco vein mottling virus genome. Virology 204:759-769.

Pink, D. A. C., and Walkey, D. G. A. 1992a. Differentiation of pathotypes of lettuce mosaic virus. Plant Pathol. 41:5-12.

Pink, D. A. C., Lot, H., and Johnson, R. 1992b. Novel pathotypes of lettuce mosaic virus-breakdown of a durable resistance. Euphytica 63:169-174.

Pruss, G., Ge, X., Shi, X. M., Carrington, J. C., and Vance, V. B. 1997. Plant viral synergism: The potyviral genome encodes a broad-range pathogenicity enhancer that transactivates replication of heterologous viruses. Plant Cell 9:859-868.

Rajamäki, M.-L., and Valkonen, J. P. T. 1999. The $6 \mathrm{~K} 2$ protein and the $\mathrm{VPg}$ of potato virus A are determinants of systemic infection in $\mathrm{Ni}$ - 
candra physaloides. Mol. Plant-Microbe Interact. 12:1074-1081.

Reichmann, J. L., Lain, S., and Garcia, J. A. 1992. Highlights and prospects of potyvirus molecular biology. J. Gen. Virol. 73:1-16.

Revers, F., Yang, S. J., Walter, J., Souche S., Lot, H., Le Gall, O., Candresse T., and Dunez, J. 1997a. Comparison of the complete nucleotide sequences of two isolates of lettuce mosaic virus differing in their biological properties. Virus Res. 47:167-177.

Revers, F., Lot, H., Souche, S., Le Gall, O., Candresse, T., and Dunez, J. 1997b. Biological and molecular variability of lettuce mosaic virus isolates. Phytopathology 87:397-403.

Revers, F., Van der Vlugt, R. A. A., Souche, S., Lanneau, M., Lot, H., Candresse, T., and Le Gall, O. 1999a. Nucleotide sequence of the 3' terminal region of the genome of four lettuce mosaic virus isolates from Greece and Yemen. Arch. Virol. 144:1619-1626.

Revers, F., Le Gall, O., Candresse, T., and Maule, A. J. 1999b. New advances in understanding the molecular biology of plant/potyvirus interactions. Mol. Plant-Microbe Interact. 12:367-376.

Shi, X. M., Miller, H., Verchot, J., Carrington, J. C., and Vance, V. B. 1997. Mutations in the region encoding the central domain of helper component-proteinase (HC-Pro) eliminate potato virus X/potyviral synergism. Virology 231:35-42.

Vance, V. B., Berger, P. H., Carrington, J. C., Hunt, A. G., and Shi, X. M. 1995. 5' proximal potyviral sequences mediate potato virus $\mathrm{X} /$ potyviral synergistic disease in transgenic tobacco. Virology 206:583-590

Yang, S. J., Revers, F., Souche, S., Lot, H., Le Gall, O., Candresse, T., and Dunez, J. 1998. Construction of full-length cDNA clones of lettuce mosaic virus (LMV) and the effects of intron-insertion on their viability in Escherichia coli and on their infectivity to plants. Arch. Virol. 143:2443-2451. 